\title{
The Occurrence of Electron Dense Intercellular Materials and Gap Junctions in the Human Intestinal Epithelium
}

\author{
Hrroshi Suzukt, Tasuke Konno, Yutaka IGarashi and \\ Toshr Yuki Yamamoto* \\ Department of Pediatrics and *Department of Anatomy, \\ Tohoku University School of Medicine, Sendai
}

Suzuki, H., Konno, T., IGarashi, $Y$, and Yamamoto, T.Y. The Occurrence of Electron Dense Intercellular Materials and Gap Junctions in the Human Intestinal Epithelium. Tohoka J. exp. Med, 1977, 121 (4), 301-313 —- Electron microscopy of biopsy specimens from the small intestines in infants and children with various gastrointestinal disturbances revealed that the intercellular space of the mucosal epithelium was often filled with electron dense materials. Here apposed cell membranes were arranged almost parallel with each other. The dense materials also filled the space just subjacent to the epithelium to form a thick, dense layer in which the basal lamina was completely buried. The gap junctions were especially well developed in the epithelia filled with these materials. Long-period fasting of patients seemed to facilitate the occurrence of the dense materials and the formation of gap junctions._- intestinal biopsy; gap junction; intestinal epithelium; intercellular material

Peroral biopsy of the small intestine has become established as a valuable procedure in evaluation of patients with various intestinal disorders (Townley and Barnes 1973; Greene et al. 1974).

In the course of electron microscopic examination of biopsy specimens from infants and children, peculiar features of the intestinal epithelium were noted in which intercellular spaces were filled with electron dense materials and gap junctions were well developed. This paper deals with these findings.

\section{Materials and Methods}

Patients. Twenty-seven infants and children were subjected to this study. They were admitted to the Pediatric Clinic, Tohoku University Hospital, with various gastrointestinal symptoms such as diarrhea, abdominal distension and vomiting. Clinical diagnoses of these patients included colitis ulcerosa, milk intolerance, intestinal lymphangiectasia, acute diarrhea, intractable diarrhea, short bowel syndrome, idiopathic steatorrhea and congenital chloride diarrhea. The age of the patients ranged from 1 month to 9 years when examined.

Intestinal biopsy. Peroral intestinal biopsy was carried ont under fluoroscopic control at the level of several centimeters distal to the ligament of Treitz by using the Crosby-Kugler capsule. Each biopsy specimen was divided into two parts, one for electron microscopy and the other for disaccharidase assay. Tissue blocks for electron microscopy

Received for publication, October 25, 1976. 
were fixed in ice-cold $2 \%$ glutaraldehyde for $3 \mathrm{hr}$, then in ice-cold $1 \%$ osmium tetroxide for $2 \mathrm{hr}$, both in Millonig's buffer of $\mathrm{pH} 7.3$ (Millonig 1962). After dehydration in ethanol, they were transferred into propylene oxide and embedded in Epon epoxy resin (Luft 1961). Ultrathin sections were prepared and double stained with $1 \%$ uranyl acetate and lead citrate (Reynolds 1963) and examined with a JEM-100 C or a JEM-200 A electron microscope. Sections from the tissue blocks embedded in Epon were stained with $1 \%$ aqueous toluidine blue (Trump et al. 1961) for light microscopic examination. In some cases repeated biopsies were carried out at different stages of recovery to examine morphological and biochemical changes.

\section{Results and Discussion}

In all cases examined junctional complexes of the epithelia of intestinal mucosa were intact (Fig. 1). As originally noted by Farquhar and Palade (1963), the complex consisting of a tight junction, an intermediate junction and a desmosome was formed at the most apical portion of the lateral surfaces of every two adjacent epithelial cells. Small dispersed desmosomes were also found on the lateral surfaces basal to the junctional complexes.

The gap junction is a specialized region of contact between apposed cell membranes of adjacent cells which has been considered to serve as a pathway for intercellular communication (Goodenough and Revel 1970; Friend and Gilula 1972); it is widely implicated in cell-to-cell transfer of ions (ionic or electrotonic coupling) (Gilula et al. 1972; Pappas et al. 1971) and cell-to-cell transfer of cellular metabolites (metabolites coupling) (Gilula et al. 1972).

As noted in animal intestines (Staehelin 1972; Yamamoto and Watanabe 1976), all of 40 biopsy specimens from 27 patients showed that the human intestinal epithelium also possessed the gap junctions. These junctions were rather well developed in the epithelia covering the intestinal villi, but were scanty in the intestinal crypts. They might occur at any level of lateral surfaces of both columnar and goblet cells below the lower ends of the junctional complexes, particularly often on interdigitated cell membranes of adjacent columnar cells (Fig. 2). The junctional cell membranes were apposed in parallel to each other with a narrow gap intervening between them. This gap was filled with electron dense substances so that two outer leaflets of the apposed membranes were seen to be united into a single layer, approximately $60 \mathrm{~A}$ in width, together with the dense intercellular gap (Figs. 1, 3, 4 and 5).

When sectioned tangentially, this dense layer showed a granular appearance with a vague regularity in arrangement (Fig. 3 ). The multiple rotation exposure method of Markham et al. (1963) was applied to analyzing this regularity. It was revealed that each granule was surrounded by six granules, showing a hexagonal pattern as a whole. In fact only a six-step rotation gave a clear image of the arrangement of granules (Fig. 3c). The shortest center-to-center distance between adjacent granules measured 90 to $100 \mathrm{~A}$.

In 10 cases, biopsies were performed two to four times at different stages of recovery from gastrointestinal symptoms. They were of various diagnoses, such as acute diarrhea, intractable diarrhea, milk intolerance, congenital chloride 
diarrhea, and intestinal lymphangiectasia. In these repeating biopsies, development of the gap junctions was noted to alter considerably; they were found frequently at some stages and rarely at others, even in the same patient. This finding suggested that the gap junction was a variable structure depending probably upon the physiological conditions of the organ. The tight junction was also known to undergo rapid configurational changes under various physiological or experimental conditions (Orei et al. 1973; Pitelka et al. 1973; Wade and Karnovsky 1974; Montesano et al. 1975, 1976).

In 10 of the 40 biopsy specimens, intercellular spaces of the intestinal epithelia were filled with electron dense materials. These materials filled up almost entirely the intercellular spaces except for areas of the intermediate junctions, desmosomes, and some small, non-junctional areas (Figs. 1, 3, 4 and 5). The spaces filled with the materials showed a rather constant width, about 160-190 A, the apposed cell membranes being arranged in parallel with each other. The dense materials also filled a space subjacent to the basal surface of the epithelium to form a dense layer of varying thickness in which the basal lamina was completely buried (Fig. 5). The gap junctions were especially well developed in the epithelia packed with the dense materials. It seemed that in the gap junctions of the packed epithelia the dense materials were condensed, showing a high density.

The occurrence of the dense intercellular materials was noted in patients with various diseases, such as colitis ulcerosa, milk intolerance, idiopathic steatorrhea, acute diarrhea, intractable diarrhea in infancy, and agammaglobulinemia. No particular diseases could be recognized to be in a causal relation to such packing of the epithelium. It was noteworthy, however, that the packing was especially conspicuous in 3 cases of long-period fasting (19-122 days) with a total parenteral

TABLE 1. The occurrence of the dense materials and the development of gap junctions in the jejunal epithelium of five patients with total parenteral nutrition (TPN)

\begin{tabular}{|c|c|c|c|c|c|c|}
\hline Patient & $\begin{array}{c}\text { Age } \\
\text { (months) }\end{array}$ & $\begin{array}{l}\text { Days of } \\
\text { TPN prior } \\
\text { to biopsy }\end{array}$ & $\begin{array}{l}\text { Days of fasting } \\
\text { state (including } \\
\text { days with TPN) } \\
\text { prior to biopsy }\end{array}$ & $\begin{array}{c}\text { Gap } \\
\text { junction }\end{array}$ & $\begin{array}{l}\text { Electron } \\
\text { dence } \\
\text { materials }\end{array}$ & Clinical diagnosis \\
\hline 1. (F.Y.) & 16 & 19 & 19 & Het & H & $\begin{array}{l}\text { Colitis ulcerosa with } \\
\text { immunodeficiency }\end{array}$ \\
\hline \multirow[t]{3}{*}{ 2. (S.M.) } & 3 & - & 6 & + & - & Intractable diarrhea \\
\hline & 4 & 30 & - & + & - & \\
\hline & 5 & - & - & + & - & \\
\hline 3. (T.N.) & 6 & 107 & 112 & H & $H$ & $\begin{array}{l}\text { Protracted diarrhea } \\
\text { after operation of } \\
\text { Hirschsprung's } \\
\text { disease }\end{array}$ \\
\hline \multirow[t]{3}{*}{ 4. (I.Y.) } & 3 & - & - & + & - & Intractable diarrhea \\
\hline & 4 & 23 & 23 & \# & H & \\
\hline & 7 & - & - & + & - & \\
\hline \multirow[t]{4}{*}{ 5. (K.K.) } & 7 & - & 3 & + & - & Intractable diarrhea \\
\hline & 10 & - & - & + & - & \\
\hline & 16 & 17 & - & + & - & \\
\hline & 19 & 55 & 5 & + & - & \\
\hline
\end{tabular}


nutrition (Table 1) (Suzuki et al. 1974; Arakawa et al. 1976). A long-period fasting is probably a condition under which the packing is likely to occur and the formation of the gap junctions is facilitated. Conversely, the electron dense materials and the well developed gap junctions were also observed in 2 specimens which showed many ampullar dilatations of intercellular spaces containing lipid droplets (Fig. 5b).

There have been no reports within our literature survey of the vertebrates in which it was demonstrated that intercellular spaces of the intestinal epithelium were filled with electron dense materials. In some epithelia of the invertebrates, however, dense intercellular materials were noted at the septate junction (Hudspeth and Revel 1971) or the zonula continua (Noirot and Noirot-Timothée 1972), and the electron microscopic appearance of the present cases resembled that of these junctional areas in invertebrate epithelia. The present study disclosed no evidence for the origin of dense materials. The nature and significance of the materials and their relationship to the formation of the gap junctions remain unsolved.

\section{Acknowledgment}

We thank Dr. Ts. Arakawa, Prof. of Pediatrics, Tohoku University, for his encouragement and critical reading of the manuscript, and Dr. H. Watanabe, Department of Anatomy, for his helping the electron microscopic study.

\section{References}

1) Arakawa, Ts., Tamura, T., Igarashi, Y., Suzuki, H. \& Sandstead, H.H. (1976) Zine deficiency in two infants during total parenteral alimentation for diarrhea. Amer. $J$. clin. Nut., 29, 197-204.

2) Farquhar, M.G. \& Palade, G.E. (1963) Junctional complexes in various epithelia. J. Cell Biol., 17, 375-412 .

3) Friend, D.S. \& Gilula, N.B. (1972) Variations in tight and gap junctions in mammalian tissues. J. Cell Biol., 53, 758-887.

4) Gilula, N.B., Reeves, O.R. \& Steinbach, A. (1972) Metabolic coupling, ionic coupling and cell contacts. Nature (Lond.), 235, 262-265.

5) Goodenough, D.A. \& Revel, J.P. (1970) A fine structural analysis of intercellular junctions in the mouse liver. J. Cell Biol., 45, 272-290.

6) Greene, H.L., Rosensweig, N.S., Luftkin, E.G., Hagler, L., Gozansky, D., Taunton, O.D. \& Herman, R.H. (1974) Biopsy of the small intestine with the Crosby-Kugler capsule. Experience in 3,866 peroral biopsies in children and adults. Amer. J. digest. Dis., 19, 189-198.

7) Hudspeth, A.J. \& Revel, J.P. (1971) Coexistence of gap and septate junctions in an invertebrate epithelium. J. Cell Biol., 50, 92-101.

8) Luft, J.H. (1961) Improvements in epoxy resin embedding methods. J. biophys. biachem. Cytol, 9, 409-414.

9) Markham, R., Frey, S. \& Hilis, G.J. (1963) Methods for the enhancement of image detail and accentuation of structure in electron microscopy. Virology, 20, 88-102.

10) Millonig, G. (1962) Further observations on a phosphate buffer for osmium solutions in fixation. In: Fifth Int. Cong. for Electron Microscopy, edited by S.S. Breese, Jr., Vol. 2, Academic Press, Inc., New York and London, p. 8.

11) Montesano, R., Friend, D.S., Perrelet, A. \& Orci, L. (1975) In vivo assembly of tight junctions in fetal rat liver. J. Cell Biol., 67, 310-319. 
12) Montesano, R., Gabbiani, G., Perrelet, A.\& Orei, L. (1976) In vivo induction of tight junction proliferation in rat liver. J. Cell Biol., 68, 793-798.

13) Noirot, Ch. \& Noirot-Timothée, C. (1972) Structure fine de la bordure en brosse de l'intestin moyen chez les insectes. $J$. Microscop., 13, 85-96.

14) Orci, L., Amherdt, M., Henquin, J.C., Lambert, A.E., Unger, R.H. \& Renold, A.E. (1973) Pronase effect on pancreatic beta cells secretion and morphology. Science, 180, 647-649.

15) Pappas, G.D., Asada, Y. \& Bennett, M.V.L. (1971) Morphological correlates of increased coupling resistance at an electrotonic synapse. J. Cell Biol., 49, 173-188.

16) Pitelka, D.R., Hamamoto, S.T., Duafala, J.G. \& Nemanic, M.K. (1973) Cell contacts in the mouse mammary gland. 1. Normal gland in postnatal development and the secretory cycle. $J$. Cell Biol., 56, 797-818.

17) Reynolds, E.S. (1963) The use of lead citrate at high $\mathrm{pH}$ as electron-opaque stain in electron microscopy. J. Cell Biol., 17, 208-212.

18) Staehelin, L.A. (1972) Three types of gap junctions interconnecting intestinal epithelial cells visualized by freeze-etching. Proc. nat. Acad. Sci. (Wash.), 69, 1318 1321 .

19) Suzuki, H., Nakagawa, H., Hirono, H. \& Konno, T. (1974) Electron microscopic finding of jejunal mucosa of infants with essential fatty acid deficiency. Rinsho Shoni Igaku (Jap.), 22, 8-18.

20) Townley, R.R.W. \& Barnes, G.L. (1973) Intestinal biopsy in childhood. Arch. Dis. Child., 48, 480-482.

21) Trump. B.F., Smuckler, E.A. \& Benditt, E.P. (1961) A method for staining epoxy sections for light microscopy. J. Ultrastruct. Res., 5, 343-348.

22) Wade, J.B. \& Karnovsky, M.J. (1974) Fracture faces of osmotically disrupted zonulae occludentes. J. Cell Biol., 62, 344-350.

23) Yamamoto, T.Y. \& Watanabe, H. (1976) Membrane modifications for the cell junction in the mucosal epithelia of the rat small intestine: a freeze-tch study. In: Recent Progress in Electron Microscopy of Cells and Tissues, edited by E. Yamada, V. Mizuhira, K. Kurosumi \& T. Nagano, Igaku Shoin, Tokyo, pp. 244-250. 
Fig. 1. Apical portion of the intestinal epithelium from a patient (T.N.), 6-month-old boy, who had protracted diarrhea after operation of Hirschsprung's disease and received a long term hyperalimentation for 107 days before biopsy.

The junctional complex is intact. It consists of a tight junction (zonula occludens ZO), an intermediate junction (zonula adherens $\mathrm{ZA}$ ) and a desmosome (macula adherens MA). The gap junctions are also observed (arrows). The intercellular space of the epithelium is filled with electron dense materials $\left({ }^{*}\right)$ almost entirely except for the areas of junctional specialization. M, mitochondria; MV, microvilli. $\times 80,000$. 


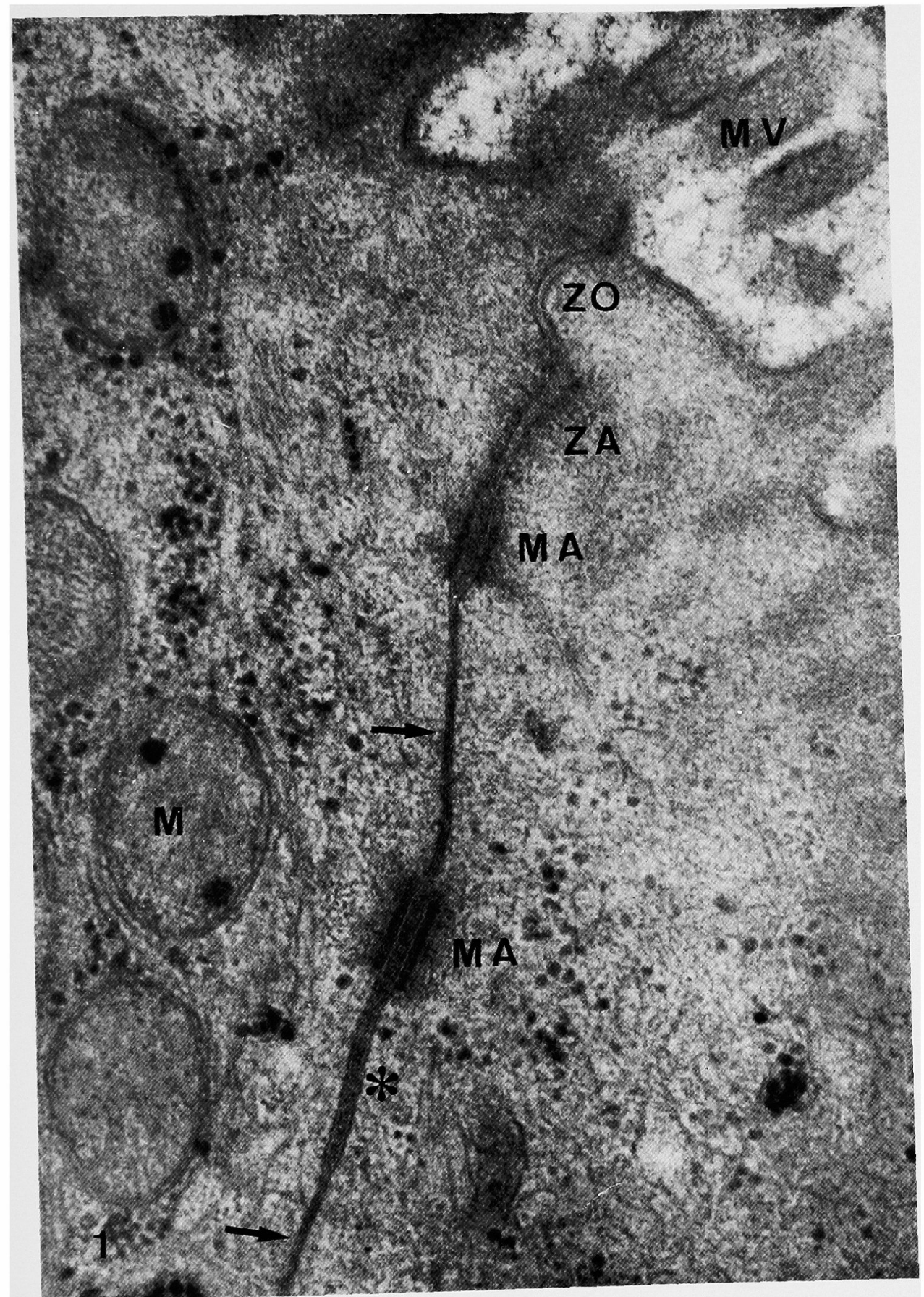


Fig. 2. The intestinal epithelium of a 7-month-old girl with acute enteritis.

The gap junctions (arrows) are observed particularly often on interdigitated cell membranes of adjacent columnar cells. $\mathrm{M}$, mitochondria; $\mathrm{N}$, nucleus. $\times 88,000$. 


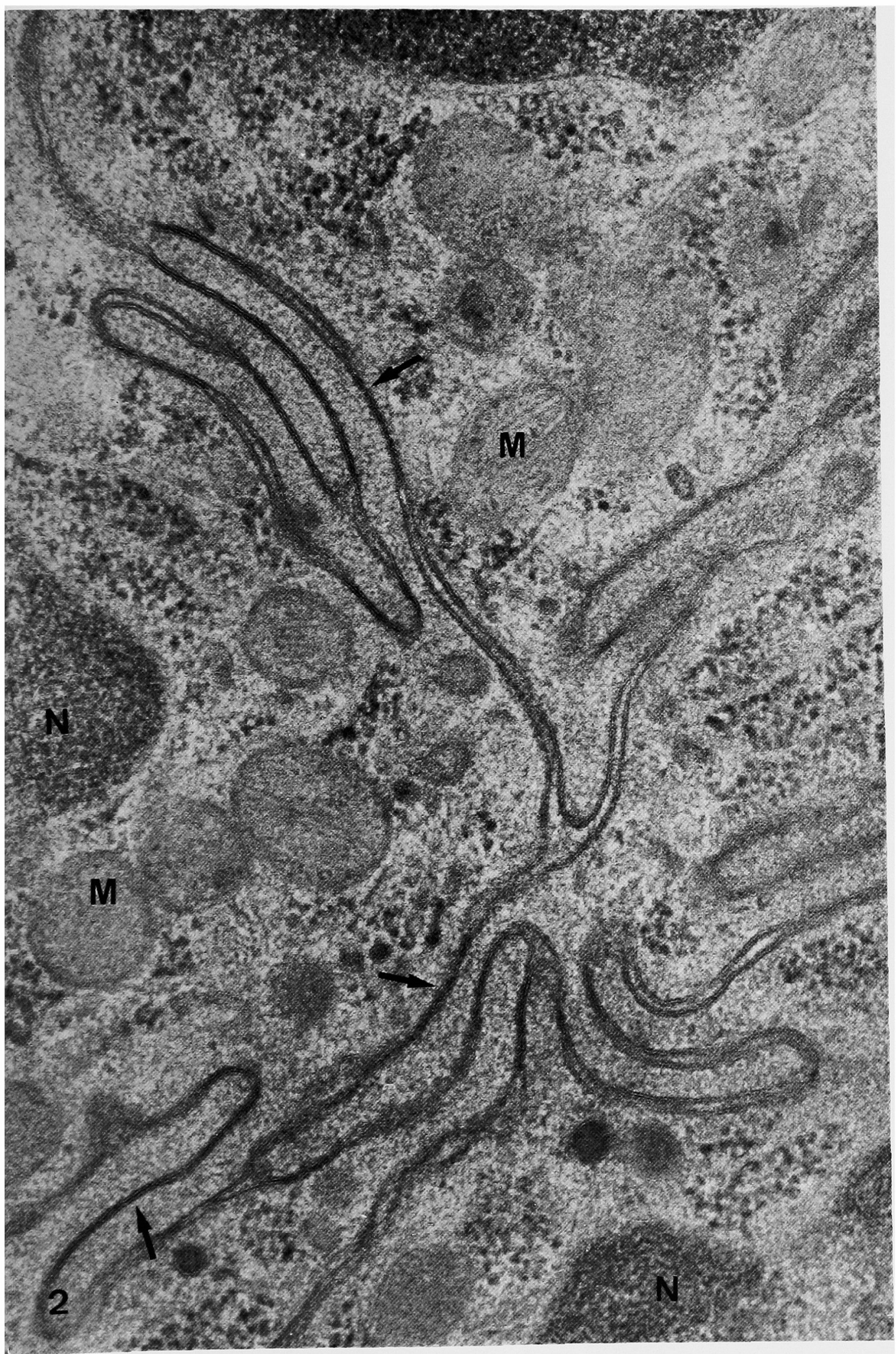


Fig. 3. A higher magnification of the gap junction. In a tangential section the junction shows a vague granular appearance; each granule is surrounded by six granules, showing a hexagonal pattern (inset a). The number of the surrounding granules is confirmed by the photographic rotation method of Markham. Only a six-step rotation (inset C) gives a clear image of the arrangement of granules. Compare with a fivestep rotation and a seven-step rotation shown in inset $b$ and $d$. In a cross section the junctional cell membranes are apposed in parallel to each other with a narrow gap intervening between them. The gap is filled witb electron dense materials. $\times 250,000$; insets $\times 1,000,000$.

Fig. 4. A higher magnification of intercellular spaces of the intestinal epithelium filled with electron dense materials. Note that the spaces filled with the materials show a rather constant width, 160-190 A, the apposed cell membranes running in parallel to each other. The gap junctions are especially well developed. $\times \mathbf{2 3 0 , 0 0 0}$. 


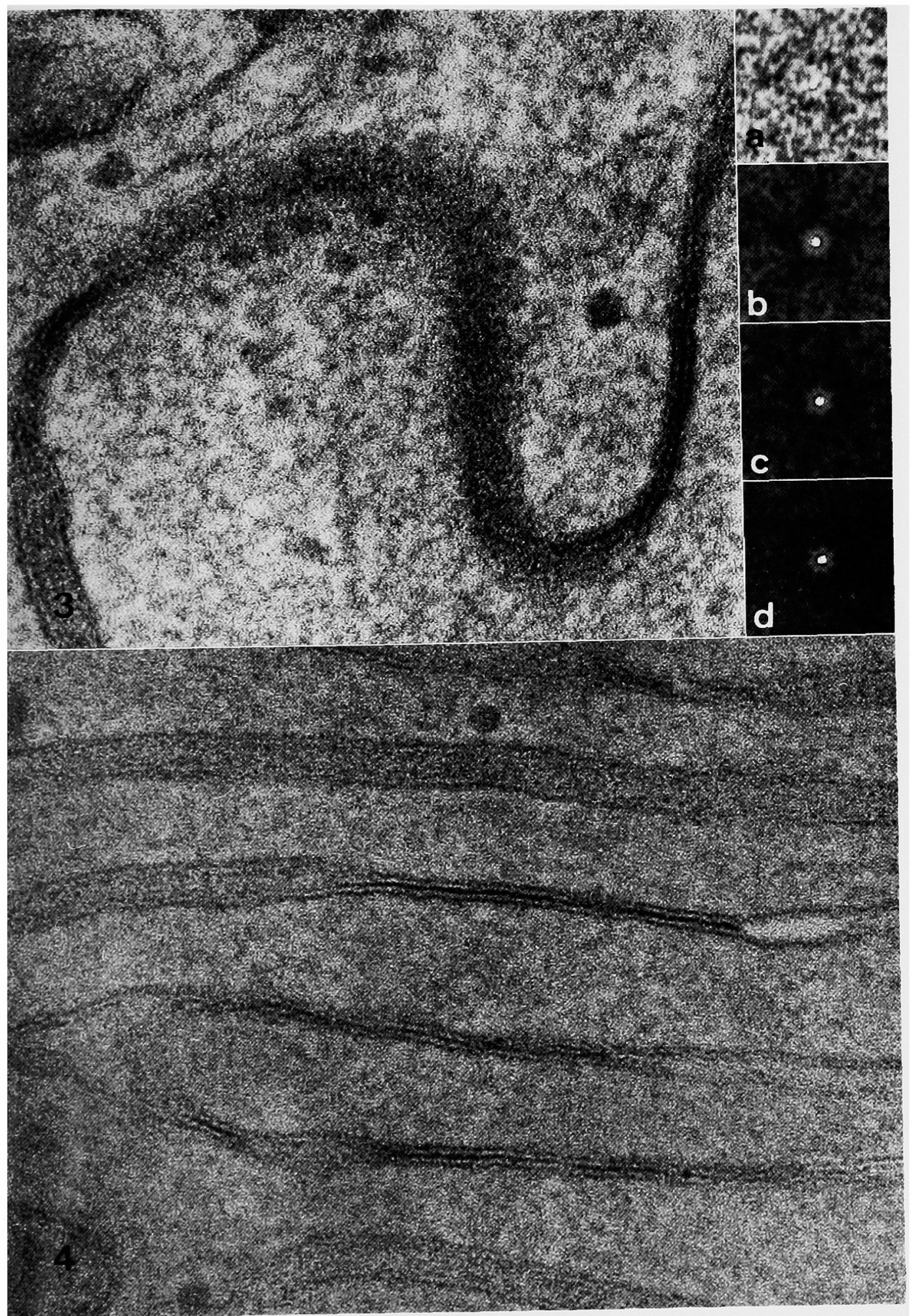


Fig. 5. Basal portion of the intestinal epithelium.

5a. Electron dense materials fill up a space subjacent to the basal surface of the epithelium to form a dense layer in which the basal lamina is completely buried. The materials also fill almost entirely the intercellular spaces except for some small nonjunctional areas (arrow). This specimen was obtained from a patient with colitis ulcerosa fasting for 19 days before biopsy. BL, basal lamina. $\times 20,000$.

5b. Note an ampulla-like dilatation of intercellular space containing lipid droplets and the electron dense materials in the remaining spaces. Well developed gap junctions are also observed (arrow). This specimen was obtained from a patient with blind loop syndrome. BL, basal lamina. $\times 60,000$. 


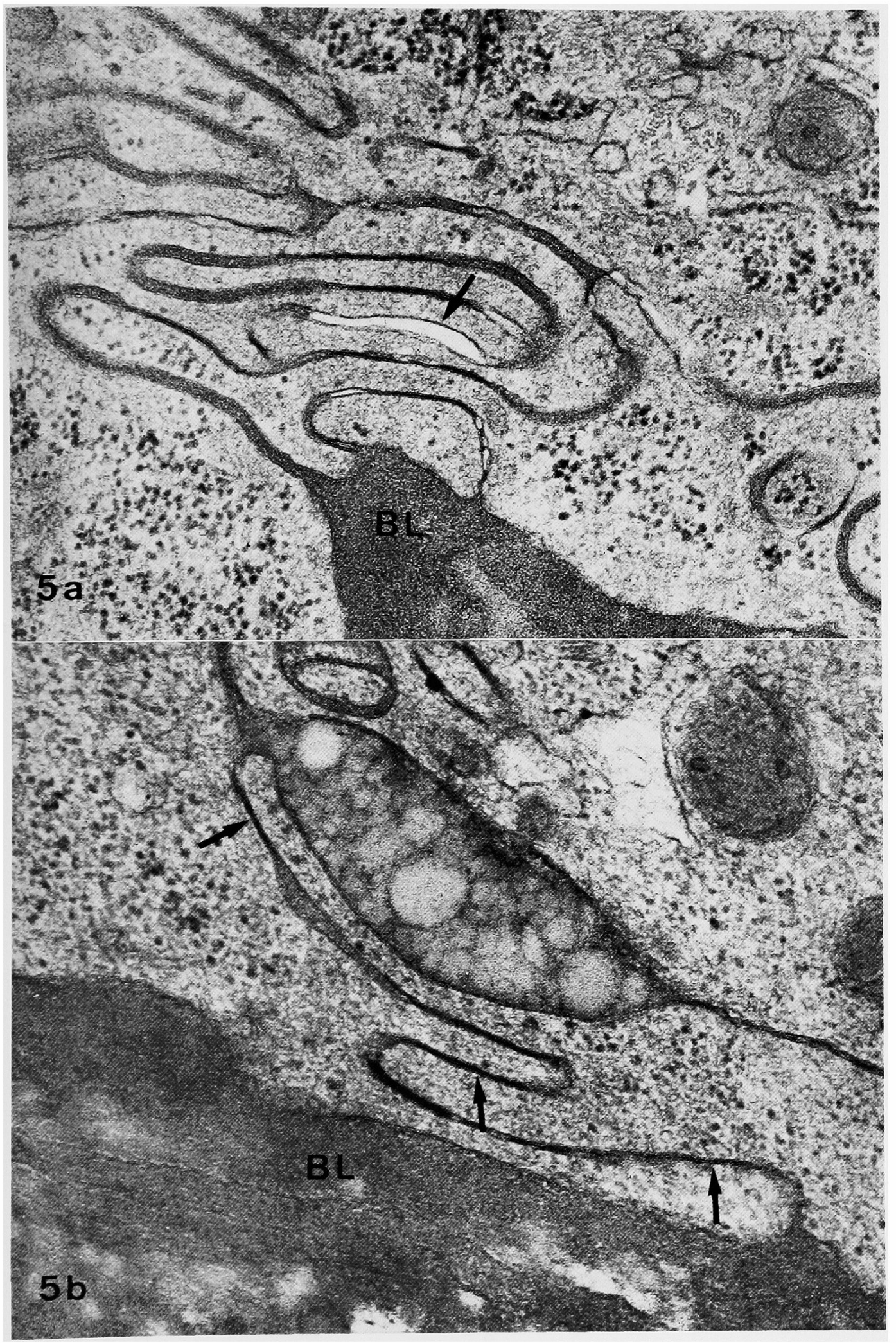

